\title{
Do Thinking Styles Contribute to Academic Achievement Beyond Self-Rated Abilities?
}

\author{
LI-FANG ZHANG \\ Department of Education \\ The University of Hong Kong
}

\begin{abstract}
This research identifies individual differences in academic achievement attributable to thinking styles over and above what can be explained by self-rated abilities. Participants were 209 university students from Hong Kong and 215 university students from mainland China. Participants responded to the Thinking Styles Inventory (Chinese version) that is based on Sternberg's theory of mental self-government (R. J. Sternberg, 1988). They also rated their own analytical, creative, and practical abilities on a 10-point scale based on R. J. Sternberg's (1985) triarchic theory of human intelligence. Participants' academic achievement scores were also used. The prediction that thinking styles statistically predict academic achievement was supported by data from both Hong Kong and mainland China. Academic achievement and thinking styles are related differently in the two groups. Implications of these findings for both teaching and research are discussed.
\end{abstract}

Key words: academic achievement, self-rated abilities, thinking styles

WHY DO SOME STUDENTS GET STRAIGHT As in school, whereas others with equal abilities flunk out? There are many ways to answer this question because there are various ways of explaining individual differences in academic achievement. Traditionally, many psychologists and educators have attributed students' successes and failures in academic achievement mainly to individual differences in abilities. In the past few decades, scholars have been examining other factors that affect students' learning outcomes.

One of the major interesting factors investigated is the "style" construct. Many theories of styles have been postulated (for a detailed review, see Jonassen \& Grabowski, 1993; Sternberg \& Zhang, 2001). These theories of styles, although different, have one thing in common: They all make a distinction between style and ability. Style refers to preferences-things one likes to do-

I am grateful to the Wu Jieh-Yee Research Fund administered by The University of Hong Kong for supporting this work. I extend very special thanks to Robert J. Sternberg for his constructive comments on a preliminary draft of this article.

Address correspondence to Li-fang Zhang, Department of Education, The University of Hong Kong, Pokfulam Road, Hong Kong; lfzhang@hkucc.hku.hk (e-mail). 
whether or not one does them well. However, abilitiy refers to things one can do-a skill or skill combinations.

Research based on theories of styles has indicated that style plays an important role in student learning. For example, Satterly (1976) showed a relation between field independence and reading achievement. Bishop-Clark (1995) investigated the effects of cognitive styles on students' achievement in computer programming. Atkinson (1998) found that students' cognitive style affected their performance in technology project work.

Furthermore, investigators are beginning to pay more attention to cross-cultural differences (e.g., Hansen-Strain, 1992; Katz, 1988; Vernon, 1984) in styles within both academic and nonacademic settings. However, these studies (e.g., Bentley, 1977; Chiu, 1972; Foxall \& Payne, 1989; Huang \& Chao, 1998) were based mostly on theories that address dichotomous styles. For example, Huang and Chao compared the cognitive styles of reflectivity and impulsivity between Chinese and American students.

In the late 1980s and early 1990s, two theories of styles that address multiple dimensions of styles were proposed. One is Riding's (1991a, 1991b) theory of cognitive style dimensions (verbal imagery and wholist analytic); the other is Sternberg's $(1988,1990,1994,1997)$ theory of mental self-government. This latter is the principal theoretical foundation for my research work for this article.

The theory of mental self-government addresses people's thinking styles, which may be used in many settings, including university, home, and community. Essentially, this theory concerns the notion that people need to govern or manage their everyday activities. There are many ways of doing so; whenever possible, people choose styles of managing themselves that they are comfortable with. Still, people are at least somewhat flexible in their use of styles, and try, with varying degrees of success, to adapt themselves to the stylistic demands of a given situation. Thus, an individual with one preference in one situation may have a different preference in another situation. Moreover, styles may change with time and with life demands. Thinking styles are at least in part socialized (Sternberg, 1994, 1997), suggesting that, to some extent, they can be modified by the environment in which people reside. Sternberg's theory addresses 13 thinking styles that fall along 5 dimensions of mental self-government: functions, forms, levels, scopes, and leanings.

Functions. As in government, there are three functions in people's mental selfgovernment: legislative, executive, and judicial. A person with a legislative style likes to be engaged in tasks that require creative strategies. A person with an executive style tends to focus more on the implementation of tasks with set guidelines. A person with a judicial style is more concerned with evaluating the products of others' activities.

Forms. Also, as in government, a person's mental self-government takes four different forms: monarchic, hierarchical, oligarchic, and anarchic. A person with a 
monarchic style prefers to be engaged in tasks that allow a complete focus on one thing at a time. By contrast, a person with a hierarchical style tends to distribute attention to several prioritized tasks. A person with an oligarchic style also likes to work toward multiple objectives within the same time frame but may not like to set priorities. Finally, a person with an anarchic style enjoys working on tasks that would allow flexibility as to what, where, when, and how one works.

Levels. As with a government, human beings' mental self-government also operates at two different levels: global and local. A person with a global style tends to pay more attention to the overall picture of an issue and to abstract ideas. A person with a local style enjoys being engaged in tasks that require work with concrete details.

Scopes. Also, as in a government, in a society, the human mind deals with internal and external matters. A person with an internal style enjoys being engaged in tasks that allow himself or herself to work independently. A person with an external style likes to be engaged in tasks that provide opportunities for developing interpersonal relationships.

Leanings. Finally, in mental self-government, there are two leanings: liberal and conservative. A person with a liberal style enjoys being engaged in tasks that involve novelty and ambiguity, whereas a person with a conservative style tends to adhere to the existing rules and procedures in task performance.

The theory of mental self-government possesses several characteristics. First, the styles it specifies fall along five dimensions rather than one. Second, styles are perceived as falling along continua rather than as being dichotomous. Third, styles are not regarded as "good" or "bad" in themselves. The utility of a style for an individual interacts with the task the individual is performing and the situation in which the task is performed. Finally, the theory yields a profile of styles for each individual, rather than merely the identification of a single style.

The theory has been tested among U.S. secondary school students and teachers and among Hong Kong university students and school teachers. Several measures have been constructed based on the theory. Among them, the Thinking Styles Inventory (TSI; Sternberg \& Wagner, 1992) is the one that has been used most frequently in previous studies.

Results of previous studies have indicated that the TSI is a reliable and valid measure for assessing the thinking styles proposed in the theory among students and teachers in both the United States and Hong Kong. The internal consistency reliabilities of the scales are generally satisfactory, ranging from the high .50s to the low .80s. Factor analyses have generally, if not completely, supported the structure of the theory. In two of the studies, five factors (obtained by a principal-axis factor analysis with an oblique rotation) accounted for $77 \%$ (Sternberg, 
1994) and 78\% (Zhang, 1999) of the variance in the data, respectively. The remaining studies indicated that the TSI scales are correlated with one another in the expected directions and that most of the correlation coefficients are statistically significant.

The usefulness of the measures has also been assessed in educational settings. In the United States, Sternberg and Grigorenko (1995; Grigorenko \& Sternberg, 1997) have conducted a series of studies. In their first study, Sternberg and Grigorenko found that teachers teaching at lower grade levels were more legislative but less executive than were teachers at higher grade levels. They also found that teachers who had taught longer were more executive, local, and conservative than teachers who had taught for a shorter time. Furthermore, it was found that humanities teachers were more liberal than were science teachers.

A second set of findings suggested significant relationships of students' thinking styles with students' characteristics, such as their socioeconomic status (SES) and birth order (Sternberg \& Grigorenko, 1995). Specifically, students of higher SES scored higher on the legislative style than did students of lower SES. Likewise, students who were later-borns scored higher on the legislative style than did students who were born earlier. A third data set suggested that teachers inadvertently favored students who have thinking styles similar to their own (Sternberg \& Grigorenko, 1995). In a more recent investigation, Grigorenko and Sternberg (1997) found that certain thinking styles statistically contributed to the prediction of academic performance beyond ability tests. Their study also suggested that students with particular thinking styles did better on some forms of evaluation than on others.

In Hong Kong, this theory was used in three studies (Zhang, 1999; Zhang \& Sachs, 1997; Zhang \& Sternberg, 1998). The results of these studies suggested that the thinking styles, as defined by Sternberg's theory, also can be identified among university students in Hong Kong. Results from these studies indicated that students' thinking styles are different, depending on such variables as age, sex, college class, college major, and travel experience. For example, older students scored significantly higher on the judicial thinking style than did their younger counterparts. Participants with more teaching experience (measured by the length of time in teaching) and those with more travel experience scored significantly higher on the legislative and liberal thinking styles.

In a recent study of 622 Hong Kong university students, Zhang and Sternberg (1998) found that thinking styles statistically predicted academic achievement over and above self-rated abilities. For example, higher achievement was positively correlated with the use of conservative, hierarchical, and internal styles of thinking. Higher achievement was negatively correlated with the use of legislative, liberal, and external styles of thinking.

However, research on the incremental validity of thinking styles beyond ability (and self-rated abilities) is limited to the two aforementioned studies (Grigorenko \& Sternberg, 1997; Zhang \& Sternberg, 1998). Can the findings in 
Hong Kong be replicated for a different sample from Hong Kong? Do thinking styles contribute to academic achievement beyond self-rated abilities among university students in mainland China? Are there cultural differences in the way that thinking styles are related to academic achievement? In the present study I answer these questions by presenting the results of the study of two samples of university students, one each from Hong Kong and mainland China.

I made three predictions. First, self-rated abilities will statistically predict academic achievement. Second, thinking styles will statistically predict academic achievement beyond what can be explained by self-rated abilities. Both of these predictions are based on previous research findings in the literature. Third, I predicted that there will be cross-cultural differences in the relationship between thinking styles and achievement. My anticipation of cross-cultural differences is based on the argument that thinking styles are at least in part socialized (e.g., Hale, 1983; Hunt, 1964; Ramirez, Castaneda, \& Herold, 1974; Saracho, 1993; Shipman, 1973; Sternberg, 1997; Steward \& Steward, 1974).

Each of the two cultures chosen for this study has unique characteristics that would help shape the thinking styles of university students. For example, the mainland Chinese culture has been known for its values of ancestor worship, the familial model of sociopolitical order, and the unity of ruling and teaching (Nathan, 1993). Therefore, people in mainland China should tend to be more oriented to authority. In an educational context, because most examinations require students to reproduce what they have been taught, those students who prefer to carry out learning tasks by following closely their teachers' instructions (the executive style) and by adhering to existing rules and procedures (the conservative style) should perform better academically.

Hong Kong people are known for holding the "egotistical individualism" ethos (Leung, 1996, p. 52). In an educational context, individual effort is much more appreciated than is collective effort. Thus, I predicted that those students who prefer to work independently (the internal style) would perform better academically. Based on previous findings among Hong Kong university students (Zhang \& Sternberg, 1998), I also predicted that students who prefer the hierarchical thinking style would have better academic achievement, whereas students who prefer the legislative, judicial and liberal thinking styles would have lower academic achievement.

\section{Method}

\section{Participants}

Two independent groups of entering freshmen from three higher educational institutions participated in the study. The first consisted of 209 students (71 men and 138 women, $M$ age $=19$ years) from a research university in Hong Kong. The second group consisted of 215 students ( 114 men and 101 women, $M$ age $=19$ years) from two research-oriented higher educational institutions in mainland China. 


\section{Measures}

Self-rated abilities. The participants rated their own abilities on a 10-point scale. The three kinds of self-rated abilities are analytical, creative, and practical, based on Sternberg's (1985) triarchic theory of human intelligence.

Achievement measures. Because of the different grading systems in Hong Kong and mainland China, a different achievement measure was used for the two groups. For the Hong Kong group, I used the participants' scores on the advanced level tests, which serve as university entrance examination scores in Hong Kong. For the mainland China group, I used the average scores of the participants' university entrance examination.

Thinking Styles Inventory. The TSI (Sternberg \& Wagner, 1992) is a self-report test consisting of 65 items on 13 scales, with 5 items per scale. For each item, the participants were asked to rate themselves on a 7-point scale ranging from 1 indicating that the statement did not describe them at all to 7 indicating that the statement characterized them extremely well. In 1996, the TSI was translated and back-translated between English and Chinese. In the current study I used the Chinese version. The 13 scales correspond to the 13 types of thinking styles illustrated in the theory of mental self-government. One sample item from each of the 13 scales is given in the Appendix.

As discussed earlier, the TSI has proven to be a reliable and valid measure of thinking styles for both U.S. and Hong Kong students. In the present study, the internal consistency reliability coefficients for the monarchic and anarchic styles were relatively low across both cultural groups. Therefore, these two scales were excluded in further analyses. The means, standard deviations, and the alpha coefficients of the remaining 11 scales are given in Table 1.

\section{Preliminary Analyses}

I conducted preliminary analyses to check the equivalence of the 11 scales across the two cultural groups. A factor analysis was carried out for each data set followed by a computation of an index of agreement. Each data set resulted in a four-factor solution. The variance accounted for was $70 \%$ for both the Hong Kong group and the mainland Chinese group. The 11 scales clustered in a reasonably similar fashion across the two groups. Also, the four factors make substantive sense. Detailed results of these factor analyses are given in Table 2.

The Tucker's Phi values (index of agreement) for the 11 scales are .42 ( $p<$ .001 , legislative), .51 ( $p<.05$, executive), .29 (nonsignificant, judicial), .39 ( $p<$ .001 , global), .24 (nonsignificant, local), .43 ( $p<.001$, liberal), .34 ( $p<.01$, conservative), .31 ( $p<.05$, hierarchical), .90 ( $p<.001$, oligarchic), .37 ( $p<.001$, internal), and .42 (nonsignificant, external). These data, although not highly desirable, are considered adequate for further data analyses. 
TABLE 1

Thinking Styles Inventory Scales: Means, Standard Deviations, and Alpha Coefficients

Scale

Hong Kong $(n=209)$

Mainland China $(n=215)$

\section{Legislative}

$M$

$S D$

$\alpha$

79

.68

5.44

Executive

$M$

4.79

$S D$

.79

.64

.86

.65

udicial

M

4.54

$S D$

.88

.72

4.68

.97

.61

$\alpha$

4.73

$M$

$S D$

.87

.73

4.87

.92

.62

$\alpha$

Oligarchic

M

$S D$

4.58

.81

$\alpha$

.64

5.00

1.07

.78

Global

M

$S D$

$\alpha$

Local

$M$

$S D$

$\alpha$

Liberal

M

$S D$

$\alpha$

Conservative

$M \quad 4.32$

4.12

.80

.63

4.62

.95

.66

$S D$

$\alpha$

4.27

.69

.43

4.59

.95

.60

4.07

4.35

.90

.49

.94

4.74

.79

1.09

.81

4.32

3.96

.85

.70

1.12

Internal

M

4.14

.74

$S D$

1.03

4.70

$\alpha$

.80

.97

External

$M$

4.28

.67

$S D$

.90

5.11

$\alpha$

.75 
TABLE 2

Factor Loadings for the Oblimin-Rotated Factor-Analysis Models

\begin{tabular}{|c|c|c|c|c|c|c|c|c|}
\hline \multirow[b]{2}{*}{ Scale } & \multicolumn{4}{|c|}{ Hong Kong $(n=209)$} & \multicolumn{4}{|c|}{ Mainland China $(n=215)$} \\
\hline & 1 & 2 & 3 & 4 & 1 & 2 & 3 & 4 \\
\hline Leg & & & -.51 & .48 & & & .55 & \\
\hline Jud & .70 & & & & .78 & & & \\
\hline Exe & & .84 & & & & .86 & & \\
\hline Hier & .82 & & & & .62 & & & \\
\hline Oli & & .67 & & & & .44 & & \\
\hline Global & & & & .89 & & & & .85 \\
\hline Local & .63 & & & & & & & -.77 \\
\hline $\mathrm{Lib}$ & & & & .58 & .81 & & & \\
\hline Con & & .90 & & & & .91 & & \\
\hline Inter & & & -.81 & & & & .79 & \\
\hline Ext & & & .72 & & & & -.72 & \\
\hline$\%$ var. & 29.80 & 17.90 & 12.56 & 9.44 & 24.62 & 21.73 & 11.93 & 11.28 \\
\hline C. var. & 29.80 & 47.69 & 60.26 & 69.70 & 24.62 & 46.36 & 58.29 & 69.57 \\
\hline Eigenvalue & 3.28 & 1.97 & 1.38 & 1.04 & 2.71 & 2.39 & 1.31 & 1.24 \\
\hline
\end{tabular}

Note Leg $=$ Legislative, Exe $=$ Executive, Jud $=$ Judicial, Hier $=$ Hierarchical, Oli $=$ Oligarchic, Lib $=$ Liberal, Con $=$ Conservative, Inter $=$ Internal, Ext $=$ External, $\%$ var. $=\%$ of Variance, $\mathrm{C}$. var. $=$ Cumulative variance. Variables with factor loadings of less than $|.40|$ have been omitted.

\section{Data Analyses}

I examined the relationships of academic achievement to self-rated abilities using stepwise multiple regression procedures, with students' self-rated abilities as the independent variable and their achievement scores as the dependent variables. I examined the relationships between thinking styles and academic achievement beyond self-rated abilities by applying hierarchical multiple-regression analysis procedures, using the thinking styles scores as the predictor of academic achievement after students' self-rated abilities had been entered into the prediction equations.

\section{Results}

\section{Relationships Between Achievement and Self-Rated Abilities}

Table 3 shows the summary statistics from the stepwise multiple regression procedures. The information includes the sample size for each test, the variance accounted for by self-rated abilities $\left(R^{2}\right)$, the weights, the correlation coefficients indicating the relationship between achievement scores and self-rated abilities, and the $F$ value of the analysis of variance for each final model. 
TABLE 3

Relationships Between Academic Achievement and Self-Rated Abilities: $R^{2} \mathrm{~s}, \beta$ Weights, and $F \mathrm{~s}$

\begin{tabular}{lccccc}
\hline \hline & \multicolumn{3}{c}{ Hong Kong $(n=209)$} & & Mainland China $(n=215)$ \\
\cline { 2 - 3 } Test & History & Use of English & Geography & & Av. U.E.E.S. \\
\hline$n$ & 59 & 208 & 70 & 202 \\
$R^{2}$ & .07 & .05 & .14 & .09 \\
$\beta_{\text {Analytical }}$ & $.27^{*}$ & $.28^{* *}$ & $.37^{* *}$ & & $.29^{* *}$ \\
$r_{1}$ & $.27^{*}$ & $.16^{* *}$ & $.37^{* *}$ & & $.29^{* * *}$ \\
$\beta_{\text {Practical }}$ & & $-.20^{*}$ & & \\
$r_{2}$ & & -.04 & & \\
$F$ & $4.53^{*}$ & $5.50^{* *}$ & $10.86^{* *}$ & & $18.77^{* * *}$ \\
$d f$ & $(1,57)$ & $(1,206)$ & $(1,68)$ & & $(1,200)$ \\
\hline
\end{tabular}

Note. Av. U.E.E.S. = Average University Entrance Examination scores. $* p<.05$. ** $p<.01$. *** $p<.001$.

In the mainland sample, I found that students' self-rated practical abilities statistically contributed to their average scores on their university entrance examinations. Moreover, achievement was significantly positively related to their selfrated ability scores. The variance accounted for by their self-rated practical ability scores was $9 \%$.

For the Hong Kong sample, because not all students took the advanced levels tests on the same subject matter, the sample sizes varied across subject matter. Tests that were taken by more than 50 participants were included in the multiple regression analysis procedures. There are six such tests (history, physics, use of English, Chinese literature, economics, and geography). Of the six statistical tests conducted, three results indicated significant relationships between achievement and self-rated ability. I found that students' self-rated analytical ability scores were significantly positively related to the achievements in history, use of English, and geography, and that students' self-rated practical ability scores were significantly negatively related to their achievement in the use of English. The variance accounted for by the self-rated abilities were $7 \%$ for history, 5\% for the use of English, and 14\% for geography.

\section{Relationships Between Achievement and Thinking Styles}

Table 4 contains the summary statistics from the hierarchical multiple regression procedures. It contains the sample size for each kind of achievement, the total variance explained by the 3 self-rated abilities $\left(R_{\text {Ability }}^{2}\right)$, the variance accounted for by self-rated abilities and thinking styles together $\left(R_{\text {Total }}^{2}\right)$, the variance uniquely contributed by thinking styles $\left(R_{\text {Style }}^{2}\right)$, weights, the correlation 
TABLE 4

Contributions of Thinking Styles to Achievement Beyond Abilities:

$R^{2}, \beta$ Weights, and $F \mathrm{~S}$

\begin{tabular}{|c|c|c|c|c|c|}
\hline \multirow[b]{2}{*}{ Test } & \multicolumn{4}{|c|}{$\begin{array}{c}\text { Hong Kong } \\
(n=209)\end{array}$} & \multirow{2}{*}{$\begin{array}{l}\text { Mainland China } \\
\quad(n=215) \\
\text { Av. U.E.E.S. }\end{array}$} \\
\hline & Physics & Use of English & Chinese literature & Geography & \\
\hline$N$ & 53 & 206 & 69 & 69 & 199 \\
\hline$R^{2}$ & .08 & .07 & .04 & .16 & .10 \\
\hline$R^{2}{ }^{\text {Ability }}$ & .13 & .08 & .24 & .06 & .03 \\
\hline$R^{2}$ Style & .21 & .15 & .28 & .22 & .13 \\
\hline$\beta_{\text {Style } 1}^{\text {Total }}$ & $-.36_{\text {External }} * *$ & $.24_{\text {Internal }} * *$ & $-.43_{\text {Judicial }} * *$ & $-.26_{\text {Liberal }} *$ & $-.13_{\text {Executive }} *$ \\
\hline $\begin{array}{l}r_{1} \\
\beta\end{array}$ & $-.35^{* *}$ & $.22^{* *} * *$ & $\begin{array}{cc}-.27^{*} & *\end{array}$ & & \\
\hline $\begin{array}{l}\beta_{\text {Style2 }} \\
r_{2}\end{array}$ & & $\begin{array}{l}-.22 \mathrm{Loccal} \\
-.15^{*}\end{array}$ & .06 Hierarchical & & \\
\hline$\beta_{\text {Style3 }}$ & & & $-.28_{\text {Legislative }}{ }^{*}$ & & \\
\hline 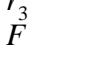 & $3.15^{*}$ & $6.89 * * *$ & $\begin{array}{l}-.20^{*} \\
4.02 * *\end{array}$ & $4.55^{* *}$ & $3.19 * *$ \\
\hline$d f$ & $(4,48)$ & $(5,200)$ & $(6,62)$ & $(4,64)$ & $(4,194)$ \\
\hline
\end{tabular}

Note. Av. U.E.E.S. = Average University Entrance Examination scores.

$* p<.05$. ** $p<.01 . * * * p<.001$.

coefficients indicating the relationship between achievement scores and the thinking styles concerned, and the $F$ value of the analysis of variance for each final model.

For the mainland China sample, the executive thinking style contributed statistically, $\beta=-.13, p<.05$, to students' average scores on their university entrance examinations. The variance accounted for by the executive style was $3 \%$ beyond what was predicted by self-rated abilities.

For the Hong Kong sample, again, only tests that were taken by more than 50 participants were included in the multiple regression analysis procedures. Of the six analyses (one for each different subject matter), four suggested significant relationships between certain thinking styles and achievement. The external thinking style was negatively correlated with students' achievement in physics, accounting for $13 \%$ of the variance beyond self-rated abilities. The internal style was positively related to the use of English, whereas the local style was negatively related to students' achievement in the use of English.

The two styles accounted for $8 \%$ of the variance beyond what was explained by self-rated abilities. Students' achievement in Chinese literature was negatively related to the judicial and legislative thinking styles but was positively related to the hierarchical thinking style. The three styles accounted for $14 \%$ of the vari- 
ance in the data. The liberal style was negatively related to students' achievement in geography, accounting for $6 \%$ of the variance beyond what was explained by self-rated abilities.

\section{Discussion}

My major goal in this research was to identify the contribution of thinking styles to academic achievement beyond self-rated abilities. A secondary goal of this study was to identify the possible cross-cultural differences in the way that thinking styles function in students' academic achievement. My three predictions were supported to different degrees.

The first prediction was partially supported. For the Hong Kong sample, not all examination scores were related to self-rated abilities. Furthermore, only selfrated analytical ability positively contributed to students' achievement in three different tests. This finding is consistent with Sternberg and Williams's (1997) finding that the analytical Graduate Record Exam score was predictive of the participants' overall quality of graduate performance. The current results also confirmed Zhang and Sternberg's (1998) finding that the higher the participants rated themselves on the analytical ability scale, the higher their achievement. This study also shows that self-rated practical ability was negatively related to students' achievement in the use of English test. Finally, self-rated creative ability scores were not significantly related to students' achievement.

One possible reason for these findings is that teachers in Hong Kong put great emphasis on analytical ability. In September 1999, after having been introduced to Sternberg's (1985) triarchic theory of human intelligence, 13 inservice teachers were informally interviewed. All the teachers indicated that among analytical, creative, and practical abilities, analytical ability is the most rewarded in Hong Kong school systems. The reason given is that teachers have to reward analytical ability because they need to prepare students for public examinations.

For the mainland sample, whereas students' self-rated practical ability statistically predicted students' achievement, neither analytical nor creative ability was related to student achievement. It is not surprising that students' creative ability was not related to their achievement. Similar to the situation in Hong Kong, creativity is not encouraged in the mainland Chinese educational system (Esman, 1990; Exum \& Lau, 1988; Ho, 1994). It is surprising, though, that practical ability rather than analytical ability pays off in academic achievement.

The second prediction was fully supported by data from mainland China and largely supported by data from Hong Kong. Self-rated ability statistically predicted students' academic achievement. However, as discussed earlier, the relationship between self-rated ability and student achievement was very limited. Thinking styles, on the other hand, demonstrated good predictive validity for academic achievement. Of all the statistical tests conducted, only two tests from 
Hong Kong did not indicate a unique contribution of thinking styles to academic achievement beyond self-rated abilities.

The third prediction was fully supported in the sense that different thinking styles statistically contributed uniquely to academic achievement in both cultural groups. Furthermore, for the Hong Kong sample, the predictions about the way particular thinking styles are related to achievement were also fully supported. In general, preferences for the use of internal (working by oneself) and hierarchical (working with a sense of priority) thinking styles tended to positively contribute to academic achievement. By contrast, the use of the legislative, judicial, and liberal styles tended to put students in an academically disadvantaged position. These findings confirmed those obtained in a previous study of Hong Kong university students (see Zhang \& Sternberg, 1998).

The predictions for the mainland Chinese group were contradicted by the current finding. Higher achievement was not positively related to the executive or conservative thinking styles. In fact, higher achievement was significantly negatively related to the employment of the executive thinking style. One of the possible reasons of this finding is that students were assessed in such a way that those students who tend to use executive or conservative thinking styles do not benefit from the assessment formats.

Two points are worth discussing regarding the findings of relationships between thinking styles and academic achievement. First, for both cultural groups, certain thinking styles statistically contributed to academic achievement beyond what was explained by self-rated ability. Although the unique contributions of thinking styles to academic achievement are only between 3\% and 24\%, these contributions tend to be greater than are found by chance and are statistically significant. Similar significant findings were obtained in an earlier study with a Hong Kong sample (Zhang \& Sternberg, 1998). Also, this finding lends support to previous research results regarding the impact of cognitive styles on academic achievement (e.g., Kim \& Michael, 1995; Robinson \& Gary, 1974; Saracho, 1991). In addition, this study went a step further than did past research in showing the importance of thinking styles in academic achievement. When self-rated abilities were controlled, certain thinking styles made unique contributions to achievement.

The second point concerns the cross-cultural differences in the relationship between academic achievement and thinking styles. This finding indicated that to succeed academically in their respective cultures, students need to have a preference for certain thinking styles. Because each culture has its own values and each educational system has a different reward system, the particular thinking styles that may contribute to academic success are different for each culture. However, by no means am I arguing that using those particular thinking styles will definitely lead to academic success. Instead, using certain thinking styles may be one of the necessary conditions for academic success in a particular cultural context.

Nevertheless, these results need to be verified by future studies, especially 
given that the predicted relationship between thinking styles and achievement for the Chinese sample was contradicted. This study, like some of the other fairly recent studies (e.g., Marton, Dall'alba, \& Tse, 1996), challenges the traditional view about the way mainland Chinese students learn. Therefore, these results can be viewed only as preliminary.

\section{Implications and Conclusion}

What are the implications of these findings? The first implication is related to the finding that thinking styles accounted for individual differences in academic achievement over and above self-rated abilities. The second is related to cross-cultural differences identified in the relationship between thinking styles and academic achievement.

The first set of implications addresses three issues: teaching and learning in the classroom, student development in interpersonal relationships, and teacher training. First, because thinking styles do make a difference in student achievement and because there are a variety of thinking styles, teachers should design a learning context that allows a variety of thinking styles. By being in a learning context that allows for a variety of thinking styles, students, regardless of their preferred ways of using their abilities, could benefit from the learning context.

However, allowing for different thinking styles does more than just facilitate students' intellectual development. It also helps to enhance student development in interpersonal relationships. For example, a teacher may ask students with different dominant thinking styles to work cooperatively. Cooperative learning provides students with the opportunity to learn from one another about more effective ways of dealing with problems (Saracho \& Spodek, 1981, 1986). In the meantime, cooperative learning also provides opportunities for students to learn how to tolerate one another's differences_-such as different values and different ways of approaching a learning task. As a result, students will learn how to work with and deal with their peers.

Furthermore, the finding that thinking styles were related to academic achievement has implications for teacher training. I suggest that all teacher-training programs include a component that introduces knowledge on cognitive/thinking/learning styles. Research has indicated that learning in at least partially matched conditions (teaching using instructional styles and materials structured to suit students' thinking and learning styles) is significantly superior to that in mismatched conditions (e.g., Ford, 1995; Grigorenko \& Sternberg, 1997; Sternberg, Grigorenko, Ferrari, \& Clinkenbeard, 1999). Therefore, I believe that an understanding of thinking styles could improve teachers' teaching and, thus, student learning.

Two implications can be derived from the findings on cross-cultural differences in thinking styles. First, the cross-cultural differences in the relationships between thinking styles and academic achievement should draw the attention of 
teachers, especially of teachers who teach in a multicultural context. These teachers should be aware of cultural group differences in thinking styles, in addition to taking into account individual differences in thinking styles. Second, the differences found in the relationships between thinking styles and academic achievement between Hong Kong and mainland Chinese students also have an important implication for research, especially cross-cultural research. This finding suggests that finer distinctions should be made among research participants rather than just labeling them from the East or West.

In this study I have shows that thinking styles contribute to academic achievement beyond what can be explained by self-rated abilities in both Hong Kong and mainland China students. This finding suggests that thinking style is an important construct that teachers should use to facilitate effective student learning. The differences in thinking styles across cultures have great potential value for the enhancement of our understanding of the forces in shaping students' cognitive development (Witkin, 1967). Exactly how do students from each culture formulate their thinking styles? What and how do cultural factors contribute to the development of thinking styles? These questions merit further qualitative investigation.

\section{REFERENCES}

Atkinson, S. (1998). Cognitive style in the context of design and technology project work. Educational Psychology, 18, 183-194.

Bentley, A. M. (1977). Symmetry in pattern reproduction by Scottish and Kenyan children. Journal of Cross-Cultural Psychology, 8, 415-424.

Bishop-Clark, C. (1995). Cognitive style, personality, and computer programming. Computers in Human Behavior, 11, 241-260.

Chiu, L. H. (1972). A cross-cultural comparison of cognitive styles in Chinese and American children. International Journal of Psychology, 7, 235-242.

Esman, A. H. (1990). Adolescence and culture. New York: Columbia University Press.

Exum, H. A., \& Lau, E. Y. (1988). Counseling style preference of Chinese college students. Journal of Multicultural Counseling and Development, 16, 84-92.

Ford, N. (1995). Levels and types of mediation in instructional systems: An individual differences approach. International Journal of Human-Computer Studies, 43, 241-259.

Foxall, G. R., \& Payne, A. F. (1989). Adaptors and innovators in organizations: A crosscultural study of the cognitive styles of managerial functions and subfunctions. Human Relations, 42, 639-649.

Grigorenko, E. L., \& Sternberg, R. J. (1997). Styles of thinking, abilities, and academic performance. Exceptional Children, 63, 295-312.

Hale, J. (1983). Black children: Their roots, culture and learning styles. In O. N. Saracho \& B. Spodek (Eds.), Understanding the multicultural experience in early childhood education (pp. 17-34). Washington, DC: National Association for the Education of Young Children.

Hansen-Strain, L. (1992). Educational implications of group differences in cognitive style: Evidence from pacific cultures. In S. Iwawaki, Y. Kashima, \& K. Leung (Eds.), Innovations in cross-cultural psychology (pp. 226-236). Amsterdam, the Netherlands: Swets \& Zeitlinger. 
Ho, D. Y. F. (1994). Filial piety, authoritarian moralism, and cognitive conservatism in Chinese societies. Genetic, Social, and General Psychology Monographs, 120, 347-365.

Huang, J. Y., \& Chao, L. (1998). A study of reflectivity and impulsivity of Chinese and American university students. Perceptual and Motor Skills, 86, 440-442.

Hunt, J. McV. (1964). How children develop intellectually. Children, 11, 83-91.

Jonassen, D. H., \& Grabowski, B. L. (1993). Handbook of individual differences: Learning and instruction. Hillsdale, NJ: Erlbaum.

Katz, N. (1988). Individual learning style: Israeli norms and cross-cultural equivalence of Kolb's Learning Style Inventory. Journal of Cross-Cultural Psychology, 19, 361-379.

Kim, J., \& Michael, W. B. (1995). The relationship of creativity measures to school achievement and to preferred learning and thinking style in a sample of Korean high school students. Educational and Psychological Measurement, 55, 60-74.

Leung, B. K. P. (1996). Perspectives on Hong Kong society. New York: Oxford University Press.

Marton, F., Dall'Alba, G., \& Tse, L. K. (1996). Memorizing and understanding: The keys to the paradox. In D. A. Watkins \& J. B. Biggs (Eds.), The Chinese learner: Cultural, psychological, and contextual influences (pp. 69-83). Hong Kong: Comparative Education Research Center and Australia: The Australian Council for Educational Research.

Nathan, A. J. (1993). Is Chinese culture distinctive-A review article. The Journal of Asian Studies, 52, 923-936.

Ramirez, M., Castaneda, A., \& Herold, P. L. (1974). Introduction to cognitive styles, new approaches to bilingual-bicultural development. (ERIC Document Reproduction Service No. ED 1089-497).

Riding, R. (1991a). Cognitive style analysis. Birmingham, AL: Learning and Training Technology.

Riding, R. (1991b). Cognitive style analysis user manual. Birmingham, AL: Learning and Training Technology.

Robinson, J. E., \& Gary, J. L. (1974). Cognitive style as a variable in school learning. Journal of Educational Psychology, 66, 793-799.

Saracho, O. N. (1991). Teaching expectations and cognitive style: Implications for students' academic achievement. Early Child Development and Care, 77, 97-108.

Saracho, O. N. (1993). Sociocultural perspectives in the cognitive styles of young students and teachers. Early Child Development and Care, 84, 1-17.

Saracho, O. N., \& Spodek, B. (1981). The teachers' cognitive styles and their educational implications. Educational Forum, 45, 153-159.

Saracho, O. N., \& Spodek, B. (1986). Cognitive styles and children's learning: Individual variation in cognitive processes. In L. G. Katz (Ed.), Current topics in early childhood education (Vol. XI, pp. 177-194). Norwood, NJ: Alex.

Satterly, D. J. (1976). Cognitive styles, spatial ability, and school achievement. Journal of Educational Psychology, 68, 36-42.

Shipman, V. C. (1973). Disadvantaged children and their first school experiences: Interim report. Princeton, NJ: Educational Testing Services.

Sternberg, R. J. (1985). Beyond IQ: A triarchic theory of human intelligence. New York: Cambridge University Press.

Sternberg, R. J. (1988). Mental self-government: A theory of intellectual styles and their development. Human Development, 31, 197-224.

Sternberg, R. J. (1990). Metaphors of mind: Conceptions of the nature of intelligence. New York: Cambridge University Press.

Sternberg, R. J. (1994). Thinking styles: Theory and assessment at the interface between 
intelligence and personality. In R. J. Sternberg \& P. Ruzgis (Eds.), Intelligence and personality. New York: Cambridge University Press.

Sternberg, R. J. (1997). Thinking styles. New York: Cambridge University Press.

Sternberg, R. J., \& Grigorenko, E. (1995). Styles of thinking in the school. European Journal for High Ability, 6, 201-219.

Sternberg, R. J., Grigorenko, E. L., Ferrari, M., \& Clinkenbeard, M. (1999). A triarchic analysis of an aptitude-treatment interaction. European Journal of Psychological Assessment, 15, 1-11.

Sternberg, R. J., \& Wagner, R. K. (1992) Thinking Styles Inventory. Unpublished test, Yale University, New Haven, CT.

Sternberg, R. J., \& Williams, W. M. (1997). Does the Graduate Record Examination predict meaningful success in the graduate training of psychologists? A case study. American Psychologist, 52, 630-641.

Sternberg, R. J., \& Zhang, L. F. (Eds.). (2001). Perspectives on thinking, learning, and cognitive styles. Mahwah, NJ: Erlbaum.

Steward, M. S., \& Steward, D. S. (1974). Effect of social distance on teaching strategies of Anglo-American and Mexican-American mothers. Developmental Psychology, 10, 797-807.

Vernon, P. E. (1984). Intelligence, cognitive styles, and brain lateralization. International Journal of Psychology, 19, 435-455.

Witkin, H. A. (1967). Cognitive-style approach to cross-cultural research. International Journal of Psychology, 2, 233-250.

Zhang, L. F. (1999). Further cross-cultural validation of the theory of mental self-government. The Journal of Psychology, 133, 165-181.

Zhang, L. F., \& Sachs, J. (1997). Assessing thinking styles in the theory of mental selfgovernment: A Hong Kong validity study. Psychological Reports, 81, 915-928.

Zhang, L. F., \& Sternberg, R. J. (1998). Thinking styles, abilities, and academic achievement among Hong Kong university students. Educational Research Journal, 13, 41-62.

\section{APPENDIX}

Sample Items From the Thinking Styles Inventory

Sample items $\quad$ Scale type Key characteristic

I like tasks that allow me to do things my own way.

I like situations in which it is clear what role I must play or in what way I should participate.

I like to evaluate and compare different points of view on issues that interest me.

I like to complete what I am doing before starting something else.

When undertaking some task, I like first to come up with a list of things that the task will require me to do
Legislative Being creative

Executive Being conforming

Judicial Being analytical

Monarchic Dealing with one task at a time

Hierarchical Dealing with multiple prioritized tasks 


\section{APPENDIX —Continued}

\section{Sample items}

Scale type

Key characteristic

and to assign an order of priority to

the items on the list.

I usually know what things need to be done, but I sometimes have trouble deciding in what order to do them.

Dealing with multiple
nonprioritized tasks

Anarchic Dealing with tasks at random

Global Focusing on abstract ideas

Local Focusing on concrete ideas

Internal Enjoying working independently

Enjoying working in groups

Using new ways to deal with tasks

Conservative Using traditional ways to deal with tasks
Liberal what has been done before. 